\title{
Review Article \\ Stem Cells and Gene Therapy for Cartilage Repair
}

\author{
Umile Giuseppe Longo, ${ }^{1,2}$ Stefano Petrillo, ${ }^{1,2}$ Edoardo Franceschetti,, ${ }^{1,2}$ \\ Alessandra Berton, ${ }^{1,2}$ Nicola Maffulli, ${ }^{3}$ and Vincenzo Denaro ${ }^{1,2}$ \\ ${ }^{1}$ Department of Orthopaedic and Trauma Surgery, Campus Bio-Medico University, Via Alvaro del Portillo 200, Trigoria, \\ 00128 Rome, Italy \\ ${ }^{2}$ Centro Integrato di Ricerca (CIR), Università Campus Bio-Medico, Via Alvaro del Portillo, 21, 00128, Rome, Italy \\ ${ }^{3}$ Centre for Sports and Exercise Medicine, Barts and The London School of Medicine and Dentistry, Mile End Hospital, \\ 275 Bancroft Road, London E1 4DG, UK
}

Correspondence should be addressed to Umile Giuseppe Longo, g.longo@unicampus.it

Received 15 October 2011; Accepted 6 December 2011

Academic Editor: Wasim S. Khan

Copyright (C) 2012 Umile Giuseppe Longo et al. This is an open access article distributed under the Creative Commons Attribution License, which permits unrestricted use, distribution, and reproduction in any medium, provided the original work is properly cited.

\begin{abstract}
Cartilage defects represent a common problem in orthopaedic practice. Predisposing factors include traumas, inflammatory conditions, and biomechanics alterations. Conservative management of cartilage defects often fails, and patients with this lesions may need surgical intervention. Several treatment strategies have been proposed, although only surgery has been proved to be predictably effective. Usually, in focal cartilage defects without a stable fibrocartilaginous repair tissue formed, surgeons try to promote a natural fibrocartilaginous response by using marrow stimulating techniques, such as microfracture, abrasion arthroplasty, and Pridie drilling, with the aim of reducing swelling and pain and improving joint function of the patients. These procedures have demonstrated to be clinically useful and are usually considered as first-line treatment for focal cartilage defects. However, fibrocartilage presents inferior mechanical and biochemical properties compared to normal hyaline articular cartilage, characterized by poor organization, significant amounts of collagen type I, and an increased susceptibility to injury, which ultimately leads to premature osteoarthritis $(\mathrm{OA})$. Therefore, the aim of future therapeutic strategies for articular cartilage regeneration is to obtain a hyaline-like cartilage repair tissue by transplantation of tissues or cells. Further studies are required to clarify the role of gene therapy and mesenchimal stem cells for management of cartilage lesions.
\end{abstract}

\section{Introduction}

Hyaline articular cartilage is a highly specialized tissue. The function of cartilage is to protect the bones of diarthrodial joints from friction, forces associated with load bearing and impact $[1,2]$. The peculiar problem of this tissue is its durability. Once articular cartilage is injured or degenerated, it has very limited capacities for self-repair and regeneration. In partial thickness lesions, in whom the defect is completely contained within the articular cartilage, there is no involvement of the vasculature. Consequently, chondroprogenitor cells from marrow or blood cannot reach the damaged region to repair the lesion or contribute to the healing of the tissue. The most considerable consequence of cartilage avascularity is that articular chondrocytes are not able to migrate towards the lesion and to produce reparative matrix to fill the defect.
As such, the defect is not repaired and remains permanently $[1,2]$.

Full thickness cartilage lesions result in the damage of the chondral layer and subchondral bone plate. The rupture of blood vessels promotes the formation of the hematoma at the injury site. In this condition, the repair response is promoted and the defect is filled with fibrocartilaginous tissue within weeks $[1,2]$.

Usually, in focal cartilage defects without a stable fibrocartilaginous repair tissue formed, surgeons try to promote a natural fibrocartilaginous response by using marrow stimulating techniques, such as microfracture, abrasion arthroplasty, and Pridie drilling with the aim of reducing swelling and pain and improving joint function of the patients. These procedures have demonstrated to be clinically useful and are 
usually considered as first-line treatment for focal cartilage defects [3-5].

However, fibrocartilage presents inferior mechanical and biochemical properties compared to normal hyaline articular cartilage, characterized by poor organization, significant amounts of collagen type I, and an increased susceptibility to injury, which ultimately leads to premature osteoarthritis (OA).

Therefore, as outlined in the modern literature on the subject, the aim of future therapeutic strategies for articular cartilage regeneration is to obtain a hyaline-like cartilage repair tissue by transplantation of tissues or cells $[2,3,6-8]$.

Tissue transplantation procedures such as periosteum, perichondrium, or osteochondral grafts have shown positive results for a limited number of patients, especially in the short term, but long-term clinical results are uncertain, with tissue availability for transplant that seems to be the major limitation, especially in large cartilage defects $[2,3,6-8]$. The autologous chondrocyte transplantation (ACT) procedure has been performed since 1987 in combination with a periosteal cover to treat chondral or osteochondral lesions of the knee, reporting good clinical results [9-11].

Recently, several authors improved this procedure embedding chondrocytes in a three-dimensional matrix before transplantation into cartilage defects $[4,12,13]$.

Good results have also been obtained especially regarding clinical symptoms, such as pain relief and joint motion, but none of the current treatment options has proved the capacity to reproduce the biochemical properties of articular hyaline cartilage $[3,10,14]$.

Moreover, in the last years, tissue engineering approaches have been investigated with the aim to produce cartilage grafts in vitro to facilitate regeneration of articular cartilage in vivo. While promising in vitro data have been obtained compared to current cartilage repair options, various problems remain unresolved for a successful repair associated with the formation of hyaline cartilage in vivo $[2,7,15,16]$.

\section{Gene Therapy}

The gene transfer to articular tissues was firstly described and performed by Evans et al., as a method to treat patient with rheumatoid arthritis $[17,18]$. Initial successful experiments in several animal models using retroviral-mediated gene delivery promoted subsequent clinical trials to evaluate the safety and feasibility of using gene therapy for rheumatoid arthritis $[17,18]$. The study was performed on 9 patients without any complications; all the nine participants tolerated the treatment and, in addition, in all the treated joints, intraarticular gene transfer and expression was observed $[17,18]$. The relative success of these studies suggests that this new treatment option can be used in major articular disorders for which only unsatisfactory treatment options are currently available.

Nowadays research and recent results indicate that the design of a successful genetic treatment for cartilage repair and restoration includes a refined strategy of gene delivery that takes into account the complexities of treating this particular tissue.
For the purpose of cartilage repair, potentially useful complementary DNAs (cDNAs) include members of the transforming growth factor- (TGF-) $\beta$ superfamily, including TGF- $\beta$ s 1,2 , and 3 , a number of bone morphogenetic proteins (BMPs), insulin-like growth factor- (IGF-) 1, fibroblast growth factors (FGFs), and epidermal growth factor (EGF).

Alternatively, to support production and maintenance of the proper hyaline cartilage matrix, delivery, and expression of cDNAs encoding specific extracellular matrix (ECM) components such as collagen type II, tenascin, or cartilage oligomeric matrix protein (COMP) may also be used [19].

Another class of biologics that may be useful in cartilage repair is represented by transcription factors that promote chondrogenesis or the maintenance of the chondrocyte phenotype. SOX9 and related transcription factors (i.e., LSOX5) and SOX6 have been identified as essential for chondrocyte differentiation and cartilage formation [20].

Signal transduction molecules, such as SMADs, are also known to be important regulators of chondrogenesis [21]. However, since these molecules function completely in the intracellular environment, gene transfer may represent the only way to harness these factors for repair, as they cannot be delivered in soluble form.

Other secreted proteins, such as indian hedgehog $(\mathrm{IHH})$ or sonic hedgehog $(\mathrm{SHH})$, play key roles in regulating chondrocyte hypertrophy [22] and could be beneficial for modulating the chondrocytic phenotype of grafted cells.

Prevention or treatment of cartilage loss may also require the inhibition of the activity of certain proinflammatory cytokines, such as interleukin- (IL-) 1 and tumor necrosis factor- (TNF-) $\alpha$, as these are important mediators of cartilage matrix degradation and apoptosis after trauma and disease. Therefore, anti-inflammatory or immunmodulatory mediators, such as interleukin-1 receptor antagonist (IL1Ra), soluble receptors for TNF (sTNFR) or IL-1 (sIL-1R), IL-4 or IL-10, inhibitors of matrix metalloproteinases, and others, may be administered to effectively reduce loss of repair cells and matrix [23].

Inhibitors of apoptosis or senescence, such as Bcl-2, BclXL, hTERT, i(NOS) and others, may also be beneficially employed to maintain cell populations which are capable of favourable repair responses at the injury site [24, 25]. Different candidate cDNAs may also be administered in combination, especially when favouring complementary therapeutic responses. For example, the combined administration of an anabolic growth factor (e.g., IGF-1) together with an inhibitor of the catabolic action of inflammatory cytokines (i.e., IL-1Ra) has the potential both to control the matrix degradation and to allow partial restoration of the damaged cartilage matrix [26, 27].

There are two general modes of intra-articular gene delivery, a direct in vivo and an indirect ex vivo approach. The direct in vivo approach involves the application of the vector directly into the joint space, whereas the ex vivo approach involves the genetic modification of cells outside the body, followed by retransplantation of the modified cells into the body.

The choice of which gene transfer method as to be used depends on several considerations, including the gene to 
be delivered, and the vector used. In general, in vivo and ex vivo delivery can be performed using adenovirus, herpes simplex virus, adenoassociated virus vectors, lentivirus, and nonviral vectors. Due to their inability to infect nondividing cells, retroviral vectors are more appropriate for ex vivo use. While ex vivo transfer methods are generally more invasive, expensive, and technically wearisome, they finally allow control of the transduced cells and safety testing prior to transplantation. In vivo approaches are simpler, cheaper, and less invasive, but these methods require the introduction of viruses directly into the body, which limits safety testing [28].

Towards the treatment of damaged articular cartilage, the three primary candidate cell types to target genetic modification are synovial lining cells, chondrocytes, and mesenchymal stem cells.

Direct intra-articular injection of a recombinant vector [29-31] represents the most straightforward strategy for gene delivery to diseased joints. Cartilage and synovium are the two primary tissues to be considered for this application.

Within articular cartilage, chondrocytes are present at a low density and are located at varying depths within the dense matrix. Due to this situation, it has not been possible to achieve an efficient genetic modification of chondrocytes in situ [32-35]. Conversely, gene delivery within the synovium tissue has resulted much more feasible since it is usually characterized by a thin lining of cells that covers all internal surfaces of the joint except that of cartilage. Also, because of its relatively large surface area, the synovium represents the predominant site of vector interaction. Both the implant of modified cells and direct intra-articular injection of vector promote the synthesis and release of therapeutic proteins into the joint space, which then bathe all available tissues, including cartilage.

Substantial progress has been made in defining the parameters that are critical for effective gene transfer to synovium and prolonged intra-articular expression by using different types of vectors in ex vivo and in vivo approaches. Through research conducted in the field of rheumatoid arthritis, the effectiveness of synovial gene transfer of various transgenes has been well documented [23]. Ex vivo gene delivery to joints has been taken into phase I clinical trial and shown to be feasible and safe in humans with rheumatoid arthritis $[17,36]$. Data relevant to direct intra-articular gene delivery are beginning to emerge, although to date most of the work in this field has been focused towards the study and treatment of rheumatoid arthritis, mainly because of the potential of this approach in treating OA [37], and also to expand repair methods of focal cartilage defects [28, 38-40].

For example, encouraging results have been reported for adenovirally delivered IGF-1 or IL-1Ra using animal models for OA and localized cartilage injury [32, 41].

Through both direct and ex vivo gene transfer to synovium, it is possible to obtain biologically considerable levels of transgene expression while for delivery of certain growth factors, this approach is not compatible. In fact, it was observed that adenoviral mediated delivery of TGF- $\beta 1$ or BMP-2 to the synovial lining determined osteophytes, cartilage degeneration, joint fibrosis, and significant swelling
[42-45]. In the perspective of cartilage repair, these results suggest that synovial gene transfer may be more appropriate for the delivery of chondroprotective agents rather than strong anabolic transgenes with pleiotropic effects of their products. It has been shown that this property is common to many anti-inflammatory cytokines.

For the gene-based delivery of certain intracellular proteins or growth factors, it appears that a strategy based on increased localization of the transgenes with the gene products contained in the lesion of the cartilage may be more practical. To achieve this goal, the most direct approach may be represented by implantation into a defect of a threedimensional matrix preloaded with a gene delivery vehicle, allowing infiltrating cells to acquire the vector and secrete the stimulating transgene products locally $[37,46]$.

In order to increase the healing of ligaments and bones, cartilage implants, activated genetically, have been designed [47-52]. For example, it has been seen that hydrated collagen-glycosaminoglycan matrices containing adenoviral vectors stimulate localized reporter gene expression in vivo for at least 21 days, after implantation into osteochondral defects localized in rabbit knees [50].

However, it is not known yet if this type of approach can promote an adequate biological response for repair due to the limited cell supply commonly present at the site of the cartilage lesion. To increase the graft cellularity, while preserving the feasibility of the procedure within one operative setting, autologous cells which are intraoperatively readily available, such as cells from bone marrow aspirates, could be mixed together with the genetically activated matrix. This genetically enhanced approach for tissue engineering would allow both the reduction of costs and execution time, while avoiding a significant effort for the ex vivo culture of cells $[49,50]$. Nevertheless, the lack of control over gene transfer following implantation represents a limitation for their use.

Through the use of genetically modified chondrocytes, attempts have been made to further improve the quality of repaired tissue. Although chondrocytes have shown a certain resistance to transfection with plasmid DNA, it has been observed that some lipid-based formulations increase the efficiency of DNA uptake [53]. However, viral-based vectors are capable of producing far higher levels of transgene expression with enhanced persistence. It was found that transfection of monolayer-expanded chondrocytes with viral vectors such as Moloney Murine Leukemia Virus (MLV), lentivirus, adenovirus, and AAV occurs promptly. It has also been shown that adenoviralmediated delivery of various transgenes, such as TGF- $\beta 1$, BMP-2, IGF-1, or BMP-7, stimulates the production of a cartilage-specific matrix rich in proteoglycans and collagen type II and reduces tendency towards dedifferentiation [54-58].

It has been seen that following transfer of cDNA encoding matrix molecules, such as the collagen type II minigene, an increased extracellular matrix production occurs in human fetal chondrocytes [37].

Collagen type II expression of chondrocytes in threedimensional culture in vitro has shown to be increased 
following transduction with the transcription factor SOX$9[59,60]$, whereas overexpression of the transcription factor Runx-2 (Cbfa-1) promotes chondrocyte maturation and determines a hypertrophic phenotype, expressing high levels of collagen types II and X, alkaline phosphatase, and osteogenic marker genes [61, 62].

Since it has been found that chondrocyte biology can be positively influenced by genetic modification, attention of research has focused on their efficient delivery to cartilage defects. The delivery of genetically modified chondrocytes in suspension has represented the first approach. Several studies demonstrated that after engraftment onto cartilage explants in vitro, genetically modified chondrocytes have the ability of expressing transgene products at functional levels [63].

Compared to transplanted control cells, in these systems, genetic modification with IGF-1 [64], FGF-2 [65], or SOX9 [66] resulted in a considerable resurfacing and thicker tissue containing increased levels of proteoglycans and collagen type II [53]. Moreover, adenoviral-mediated IL-1Ra gene transfer to chondrocytes led to resistance to IL-1-induced proteoglycan degradation after engraftment [67].

Genetically modified chondrocytes have also been used as an alternative to delivery in suspension with the aim of enhancing tissue engineering procedures. This approach requires the transduction/transfection in monolayer cells subsequently seeded into a matrix for further transplantation into chondral or osteochondral lesions. Several transgenes including TGF $\beta 1$, BMP-2, -4, -7, IGF-1, SOX9, among others have shown promising results in these three-dimensional culture systems due to their ability to maintain and stimulate the chondrogenic phenotype in vitro $[16,28,40]$.

Initial studies highlighted that following genetic modifications with adenoviral, AAV, retroviral, or plasmid vectors, chondrocytes had the ability to efficiently express reporter genes in chondral and osteochondral lesions, and that when the genetically modified chondrocytes were seeded in threedimensional matrices, transgene expression was extended over several weeks [68-71].

The results of efficacy studies demonstrating the effects of genetically modified chondrocytes in cartilage defects in vivo have just started to be reported.

In an ex vivo approach, adenovirally transduced chondrocytes expressing BMP-7 [54], integrated in a matrix of autogenous fibrin, were implanted into full thickness articular cartilage lesions in horses [54]. An enhanced tissue volume with increased production of a proteoglycan and collagen type II rich matrix was detected 4 weeks after surgery in the BMP-7-treated lesions, compared to control lesions treated with unrelated marker genes.

After 8 months, the mechanical features of the treated lesions as well as the levels of collagen type II and proteoglycan were however similar compared to the controls. This finding was attributed to some extent to the reduction of the number of allografted chondrocytes that persisted after 8 months in the lesions [54]. Nevertheless, these findings remain encouraging since they suggest that genetically modified chondrocytes can be used to increase a cartilage repair process in a large animal model.

\section{Mesenchymal Stem Cells}

Until recently, scientists have mainly focused on research involving two types of stem cells from humans and animals: nonembryonic "somatic" or "adult" stem cells and embryonic stem cells.

Embryonic stem cells are present in the blastocyst while adult stem cells are found in adult tissues. The normal turnover of organs that have a high intrinsic regenerative ability which include blood, skin, and intestinal epithelium is maintained by adult stem cells. Adult stem cells are generally unipotent or multipotent and they can be found in adults as well as adolescents and children.

Adult pluripotent stem cells are normally found in small numbers since they are very rare. However, they are present in several tissues including umbilical cord blood. The adult stem cells studied most extensively to date are the multipotent stem cells which are commonly referred to by their tissue origin (i.e., hematopoietic stem cells that differentiate into platelets erythrocytes, white blood cells, etc.) and the bone marrow stromal cells (also known as MSCs) $[72,73]$, which have the capacity to differentiate into connective tissue cells.

MSCs have the potential to differentiate into cells of connective tissue lineages [74] including bone [75-77], cartilage [77-79], ligament [80-82], muscle [78], fat [78, $83]$, and IVD [81, 82, 84]. It has been detected that these cells are also capable of differentiation along myogenic and neurogenic lineages, although these are not the common pathways used to prove multipotentiality of isolated MSCs.

Originally, adult MSCs were isolated from bone marrow by Pittenger et al. in 1999 [74], who demonstrated the potential for multilineage differentiation of these cells. Subsequently, a number of studies allowed to demonstrate the presence of stem cells in various adult tissues, including synovial fluid, articular cartilage, synovial membrane, periosteum, dermis, muscle, and adipose tissue.

To date, research has allowed for MSC-like progenitor cells isolation from trabecular bone, periosteum, synovium, skeletal muscle, adipose tissue, deciduous teeth $[78,80]$, and bone marrow [85].

Since no definitive markers of MSCs are available, a range of cell surface markers are normally used. These include immunopositivity for STRO-1, CD73, CD105, CD106, CD145, and CD166, associated with negative immunoreactivity for CD11b, CD31, CD34, CD45, and CD117.

Compared to the previous methods based on either density-gradient centrifugation or even simple plastic adherence, these markers allow to identify a more homogeneous population of cells.

Due to general heterogeneity of bone marrow cell populations, variable results can be obtained; however, MSCs have commonly shown the ability to differentiate along the adipogenic, chondrogenic, and osteogenic pathways. Research conducted by several authors suggests that MSCs are capable of differentiation to chondrocytes, osteoblasts, and nucleus pulposus (NP) cells of the IVD [84, 86-88]. However, since no definitive markers of NP cells are available, 
a number of chondrocyte markers, with which they share a large phenotypic similarity, are typically used.

After Pittenger et al. [74] demonstrated the chondrogenic potential of MSCs, a number of approaches promoting MSC chondrogenesis [60] such as agarose [89] and alginate [90] gels have been described and more recently a range of tissue engineering biomaterials which allow or promote chondrogenesis have also been reported.

One of the most commonly used growth factors is TGFb $[74,91]$, which has shown to promote chondrogenesis in addition to inhibiting adipogenic and osteogenic differentiation $[92,93]$.

Growth factors of the BMP family, principally BMP-7, and IGF-1 have also demonstrated the ability to promote chondrogenesis of MSCs and it has also been suggested that expansion of monolayer MSCs in medium containing FGF2 induces chondrogenesis following transfer to a $3 \mathrm{D}$ culture environment [94-97].

However, with the in vitro differentiation approaches, the complexity of the signaling pathways involved in chondrogenesis represents one of the major problems, compared to the simplicity of culture systems.

Several studies have demonstrated the importance of cellcell contact for MSC differentiation to either NP cells or chondrocytes [73] and pellet cultures mimic the mesenchymal compression that occurs during embryogenesis.

Similarly it is known that differentiation and matrix formation are induced by anabolic growth factors that exert their activity through a number of pathways, primarily the Smad and MAPKinase pathways [92, 96, 98].

The routine assessment of successful chondrogenesis is performed by the induction of SOX-9, which subsequently promotes the production of type II collagen as well as the enhanced expression of the PG aggrecan [99, 100]. Based on the similarities in the phenotype of NP cells of the IVD and articular chondrocytes [101], these markers are also used routinely to identify NP-like cells since no validated and highly specific NP marker genes are available. However, in standard in vitro culture systems MSC differentiation has shown to be unstable and it commonly leads to the expression of hypertrophic markers such as alkaline phosphatase and type X collagen [91, 102].

In terms of clinical application, the likelihood that chondrogenic differentiation may cause hypertrophy represents a problem since healthy surface and mid zone chondrocytes and NP cells do not express alkaline phosphatase nor type X collagen $[103,104]$.

This was demonstrated by Pelttari et al. [105] in pellet cultures comparing MSCs and chondrocytes, who reported that following implantation into SCID mice, the MSCs showed high levels of alkaline phosphatase and type $\mathrm{X}$ collagen expression which induced vascular invasion and calcification, while chondrocytes produced a cartilaginous matrix.

Improved differentiation or terminal differentiation inhibition may be induced with a number of growth factors. For example, it has been observed that the addition of PTHrP to TGF-b3-stimulated MSCs in poly-glycolic acid scaffolds also inhibits the expression of type $\mathrm{X}$ collagen of these cells and suppresses their terminal differentiation [106]. Also, the combination of TGF-b3 with BMP-2 has shown improved chondrogenic differentiation of MSCs compared to either growth factor alone or the combination of TGF-b3 with either BMP-4 or BMP-6 [107].

\section{Conclusions}

Hyaline articular cartilage is a highly specialized tissue. The peculiar problem of this tissue is that once articular cartilage is injured or degenerated, it has very limited capacities for self-repair and regeneration.

Usually, in focal cartilage defects without a stable fibrocartilaginous repair tissue formed, surgeons try to promote a natural fibrocartilaginous response by using marrow stimulating techniques, such as microfracture, abrasion arthroplasty, and Pridie drilling [108-111].

However, fibrocartilage presents inferior mechanical and biochemical properties compared to normal hyaline articular cartilage, characterized by poor organization, significant amounts of collagen type I, and an increased susceptibility to injury, which ultimately leads to premature OA [112-114].

The implementation of gene transfer techniques may allow to overcome the limitations of the current treatments for articular cartilage lesions. It has been shown that various approaches could be appropriate for an efficient transfer of exogenous cDNAs to cartilage lesions in vivo and for achieving sustained expression of the related gene products.

Initial efficacy studies have proven that gene-transfer techniques represent potent tools able to promote a significant biological response in vivo. However, the safety of gene transfer approaches for cartilage repair is also of particular importance because cartilage injuries are not lifethreatening. Therefore the application of this technology for clinical use is strongly dependent on the use of safe and efficient delivery systems vectors and transgenes.

Although a number of animal models for OA and other types of arthritis are available, none of them allow to predict the equivalent disease in humans and most them are linked with problems. Further studies are required to establish the role of stem cells and gene therapy for cartilage repair.

\section{References}

[1] J. A. Buckwalter and H. J. Mankin, "Articular cartilage: tissue design and chondrocyte-matrix interactions," Instructional course lectures, vol. 47, pp. 477-486, 1998.

[2] E. B. Hunziker, "Articular cartilage repair: basic science and clinical progress. A review of the current status and prospects," Osteoarthritis and Cartilage, vol. 10, no. 6, pp. 432-463, 2002.

[3] J. A. Buckwalter and H. J. Mankin, "Articular cartilage repair and transplantation," Arthritis and Rheumatism, vol. 41, no. 8, pp. 1331-1342, 1998.

[4] T. Minas, "The role of cartilage repair techniques, including chondrocyte transplantation, in focal chondral knee damage," Instructional course lectures, vol. 48, pp. 629-643, 1999.

[5] J. R. Steadman, W. G. Rodkey, and K. K. Briggs, "Microfracture to treat full-thickness chondral defects: surgical 
technique, rehabilitation, and outcomes," The journal of knee surgery, vol. 15, no. 3, pp. 170-176, 2002.

[6] S. J. M. Bouwmeester, J. M. H. Beckers, R. Kuijer, A. J. Van Der Linden, and S. K. Bulstra, "Long-term results of rib perichondrial grafts for repair of cartilage defects in the human knee," International Orthopaedics, vol. 21, no. 5, pp. 313-317, 1997.

[7] A. I. Caplan, M. Elyaderani, Y. Mochizuki, S. Wakitani, and V. M. Goldberg, "Principles of cartilage repair and regeneration," Clinical Orthopaedics and Related Research, no. 342, pp. 254-269, 1997.

[8] L. Hangody and P. Füles, "Autologous osteochondral mosaicplasty for the treatment of full-thickness defects of weightbearing joints: ten years of experimental and clinical experience," Journal of Bone and Joint Surgery A, vol. 85, no. 1, pp. 25-32, 2003.

[9] M. Brittberg, A. Lindahl, A. Nilsson, C. Ohlsson, O. Isaksson, and L. Peterson, "Treatment of deep cartilage defects in the knee with autologous chondrocyte transplantation," New England Journal of Medicine, vol. 331, no. 14, pp. 889-895, 1994.

[10] T. Minas and S. Nehrer, "Current concepts in the treatment of articular cartilage defects," Orthopedics, vol. 20, no. 6, pp. 525-538, 1997.

[11] L. Peterson, T. Minas, M. Brittberg, and A. Lindahl, "Treatment of osteochondritis dissecans of the knee with autologous chondrocyte transplantation: results at two to ten years," Journal of Bone and Joint Surgery A, vol. 85, no. 1, pp. 17-24, 2003.

[12] P. Behrens, U. Bosch, J. Bruns et al., "Recommendations for indication and application of ACT of the joined advisory board of the German Societies for Traumatology (DGU) and Orthopaedic Surgery (DGOOC)," Zeitschrift fur Orthopadie und Ihre Grenzgebiete, vol. 142, no. 5, pp. 529-539, 2004.

[13] S. Marlovits, P. Zeller, P. Singer, C. Resinger, and V. Vécsei, "Cartilage repair: generations of autologous chondrocyte transplantation," European Journal of Radiology, vol. 57, no. 1, pp. 24-31, 2006.

[14] L. Peterson, M. Brittberg, I. Kiviranta, E. L. Åkerlund, and A. Lindahl, "Autologous chondrocyte transplantation: biomechanics and long-term durability," American Journal of Sports Medicine, vol. 30, no. 1, pp. 2-12, 2002.

[15] C. K. Kuo, W. J. Li, R. L. Mauck, and R. S. Tuan, "Cartilage tissue engineering: its potential and uses," Current Opinion in Rheumatology, vol. 18, no. 1, pp. 64-73, 2006.

[16] R. Tuli, W. J. Li, and R. S. Tuan, "Current state of cartilage tissue engineering," Arthritis Research and Therapy, vol. 5, no. 5, pp. 235-238, 2003.

[17] C. H. Evans, H. J. Mankin, A. B. Ferguson et al., "Clinical trial to assess the safety, feasibility, and efficacy of transferring a potentially anti-arthritic cytokine gene to human joints with rheumatoid arthritis," Human Gene Therapy, vol. 7, no. 10, pp. 1261-1280, 1996.

[18] C. H. Evans, P. D. Robbins, S. C. Ghivizzani et al., "Gene transfer to human joints: progress toward a gene therapy of arthritis," Proceedings of the National Academy of Sciences of the United States of America, vol. 102, no. 24, pp. 8698-8703, 2005.

[19] R. M. Dharmavaram, G. Liu, R. S. Tuan, D. G. Stokes, and S. A. Jiménez, "Stable transfection of human fetal chondrocytes with a type II procollagen minigene: expression of the mutant protein and alterations in the structure of the extracellular matrix in vitro," Arthritis and Rheumatism, vol. 42, no. 7, pp. 1433-1442, 1999.
[20] V. Lefebvre, R. R. Behringer, and B. De Crombrugghe, "LSox5, Sox6 and SOx9 control essential steps of the chondrocyte differentiation pathway," Osteoarthritis and Cartilage, vol. 9, pp. S69-S75, 2001.

[21] A. Hoffmann and G. Gross, "BMP signaling pathways in cartilage and bone formation," Critical Reviews in Eukaryotic Gene Expression, vol. 11, no. 1-3, pp. 23-45, 2001.

[22] A. Vortkamp, "Interaction of growth factors regulating chondrocyte differentiation in the developing embryo," Osteoarthritis and Cartilage, vol. 9, pp. S109-S117, 2001.

[23] P. D. Robbins, C. H. Evans, and Y. Chernajovsky, "Gene therapy for arthritis," Gene Therapy, vol. 10, no. 10, pp. 902911, 2003.

[24] D. D. D’Lima, S. Hashimoto, P. C. Chen, C. W. Colwell Jr., and M. K. Lotz, "Impact of mechanical trauma on matrix and cells," Clinical Orthopaedics and Related Research, no. 391, pp. S90-S99, 2001.

[25] D. D. D'Lima, S. Hashimoto, P. C. Chen, M. K. Lotz, and C. W. Colwell Jr., "Cartilage injury induces chondrocyte apoptosis," Journal of Bone and Joint Surgery A, vol. 83, no. 2, pp. 19-21, 2001.

[26] J. L. Haupt, D. D. Frisbie, C. W. McIlwraith et al., "Dual transduction of insulin-like growth factor-I and interleukin1 receptor antagonist protein controls cartilage degradation in an osteoarthritic culture model," Journal of Orthopaedic Research, vol. 23, no. 1, pp. 118-126, 2005.

[27] A. J. Nixon, J. L. Haupt, D. D. Frisbie et al., "Gene-mediated restoration of cartilage matrix by combination insulin-like growth factor-I/interleukin-1 receptor antagonist therapy," Gene Therapy, vol. 12, no. 2, pp. 177-186, 2005.

[28] A. F. Steinert, U. Nöth, and R. S. Tuan, "Concepts in gene therapy for cartilage repair," Injury, vol. 39, no. 1, pp. 97-113, 2008.

[29] S. C. Ghivizzani, E. R. Lechman, R. Kang et al., "Direct adenovirus-mediated gene transfer of interleukin 1 and tumor necrosis factor $\alpha$ soluble receptors to rabbit knees with experimental arthritis has local and distal anti-arthritic effects," Proceedings of the National Academy of Sciences of the United States of America, vol. 95, no. 8, pp. 4613-4618, 1998.

[30] S. C. Ghivizzani, E. R. Lechman, C. Tio et al., "Direct retrovirus-mediated gene transfer to the synovium of the rabbit knee: implications for arthritis gene therapy," Gene Therapy, vol. 4, no. 9, pp. 977-982, 1997.

[31] S. C. Ghivizzani, T. J. Oligino, J. C. Glorioso, P. D. Robbins, and C. H. Evans, "Direct gene delivery strategies for the treatment of rheumatoid arthritis," Drug Discovery Today, vol. 6, no. 5, pp. 259-267, 2001.

[32] M. Cucchiarini, H. Madry, C. Ma et al., "Improved tissue repair in articular cartilage defects in vivo by rAAV-mediated overexpression of human fibroblast growth factor 2," Molecular Therapy, vol. 12, no. 2, pp. 229-238, 2005.

[33] E. Gouze, R. Pawliuk, C. Pilapil et al., "In vivo gene delivery to synovium by lentiviral vectors," Molecular Therapy, vol. 5, no. 4, pp. 397-404, 2002.

[34] T. Tomita, H. Hashimoto, N. Tomita et al., "In vivo direct gene transfer into articular cartilage by intraarticular injection mediated by HVJ (Sendai virus) and liposomes," Arthritis and Rheumatism, vol. 40, no. 5, pp. 901-906, 1997.

[35] Q. Yao, J. C. Glorioso, C. H. Evans et al., "Adenoviral mediated delivery of FAS ligand to arthritic joints causes extensive apoptosis in the synovial lining," Journal of Gene Medicine, vol. 2, no. 3, pp. 210-219, 2000.

[36] C. H. Evans, E. Gouze, J. N. Gouze, P. D. Robbins, and S. C. Ghivizzani, "Gene therapeutic approaches-transfer in vivo," 
Advanced Drug Delivery Reviews, vol. 58, no. 2, pp. 243-258, 2006.

[37] C. H. Evans, J. N. Gouze, E. Gouze, P. D. Robbins, and S. C. Ghivizzani, "Osteoarthritis gene therapy," Gene Therapy, vol. 11, no. 4, pp. 379-389, 2004.

[38] M. Cucchiarini and H. Madry, "Gene therapy for cartilage defects," Journal of Gene Medicine, vol. 7, no. 12, pp. 14951509, 2005.

[39] K. Gelse and H. Schneider, "Ex vivo gene therapy approaches to cartilage repair," Advanced Drug Delivery Reviews, vol. 58, no. 2, pp. 259-284, 2006.

[40] S. B. Trippel, S. C. Ghivizzani, and A. J. Nixon, "Genebased approaches for the repair of articular cartilage," Gene Therapy, vol. 11, no. 4, pp. 351-359, 2004.

[41] D. D. Frisbie, S. C. Ghivizzani, P. D. Robbins, C. H. Evans, and C. W. McIlwraith, "Treatment of experimental equine osteoarthritis by in vivo delivery of the equine interleukin1 receptor antagonist gene," Gene Therapy, vol. 9, no. 1, pp. 12-20, 2002.

[42] A. C. Bakker, L. A. B. Joosten, O. J. Arntz et al., "Prevention of murine collagen-induced arthritis in the knee and ipsilateral paw by local expression of human interleukin-1 receptor antagonist protein in the knee," Arthritis and Rheumatism, vol. 40, no. 5, pp. 893-900, 1997.

[43] K. Gelse, Q. J. Jiang, T. Aigner et al., "Fibroblast-mediated delivery of growth factor complementary DNA into mouse joints induces chondrogenesis but avoids the disadvantages of direct viral gene transfer," Arthritis and Rheumatism, vol. 44, no. 8, pp. 1943-1953, 2001.

[44] K. Gelse, K. Von der Mark, T. Aigner, J. Park, and H. Schneider, "Articular cartilage repair by gene therapy using growth factor-producing mesenchymal cells," Arthritis and Rheumatism, vol. 48, no. 2, pp. 430-441, 2003.

[45] Z. Mi, S. C. Ghivizzani, E. Lechman, J. C. Glorioso, C. H. Evans, and P. D. Robbins, "Adverse effects of adenovirusmediated gene transfer of human transforming growth factor beta 1 into rabbit knees," Arthritis Res Ther, vol. 5, no. 3, pp. R132-R139, 2003.

[46] J. Bonadio, "Tissue engineering via local gene delivery: update and future prospects for enhancing the technology," Advanced Drug Delivery Reviews, vol. 44, no. 2-3, pp. 185194, 2000.

[47] J. Bonadio, E. Smiley, P. Patil, and S. Goldstein, "Localized, direct plasmid gene delivery in vivo: prolonged therapy results in reproducible tissue regeneration," Nature Medicine, vol. 5, no. 7, pp. 753-759, 1999.

[48] Q. Dai, L. Manfield, Y. Wang, and G. A. C. Murrell, "Adenovirus-mediated gene transfer to healing tendonenhanced efficiency using a gelatin sponge," Journal of Orthopaedic Research, vol. 21, no. 4, pp. 604-609, 2003.

[49] C. H. Evans, "Gene therapies for osteoarthritis," Current rheumatology reports, vol. 6, no. 1, pp. 31-40, 2004.

[50] A. Pascher, G. D. Palmer, A. Steinert et al., "Gene delivery to cartilage defects using coagulated bone marrow aspirate," Gene Therapy, vol. 11, no. 2, pp. 133-141, 2004.

[51] A. Pascher, A. F. Steinert, G. D. Palmer et al., "Enhanced repair of the anterior cruciate ligament by in situ gene transfer: evaluation in an in vitro model," Molecular Therapy, vol. 10, no. 2, pp. 327-336, 2004.

[52] R. E. Samuel, C. R. Lee, S. C. Ghivizzani et al., "Delivery of plasmid DNA to articular chondrocytes via novel collagenglycosaminoglycan matrices," Human Gene Therapy, vol. 13, no. 7, pp. 791-802, 2002.
[53] H. Madry and S. B. Trippel, "Efficient lipid-mediated gene transfer to articular chondrocytes," Gene Therapy, vol. 7, no. 4, pp. 286-291, 2000.

[54] C. Hidaka, L. R. Goodrich, C. T. Chen, R. F. Warren, R. G. Crystal, and A. J. Nixon, "Acceleration of cartilage repair by genetically modified chondrocytes over expressing bone morphogenetic protein-7," Journal of Orthopaedic Research, vol. 21, no. 4, pp. 573-583, 2003.

[55] A. J. Nixon, L. A. Fortier, J. Williams, and H. Mohammed, "Enhanced repair of extensive articular defects by insulinlike growth factor-I-laden fibrin composites," Journal of Orthopaedic Research, vol. 17, no. 4, pp. 475-487, 1999.

[56] A. J. Nixon, R. A. Saxer, and B. D. Brower-Toland, "Exogenous insulin-like growth factor-I stimulates an autoinductive IGF-I autocrine/paracrine response in chondrocytes," Journal of Orthopaedic Research, vol. 19, no. 1, pp. 26-32, 2001.

[57] F. D. Shuler, H. I. Georgescu, C. Niyibizi et al., "Increased matrix synthesis following adenoviral transfer of a transforming growth factor $\beta 1$ gene into articular chondrocytes," Journal of Orthopaedic Research, vol. 18, no. 4, pp. 585-592, 2000.

[58] P. Smith, F. D. Shuler, H. I. Georgescu et al., "Genetic enhancement of matrix synthesis by articular chondrocytes: comparison of different growth factor genes in the presence and absence of interleukin-1," Arthritis and Rheumatism, vol. 43, no. 5, pp. 1156-1164, 2000.

[59] L. Ying, S. R. Tew, A. M. Russell, K. R. Gonzalez, T. E. Hardingham, and R. E. Hawkins, "Transduction of passaged human articular chondrocytes with adenoviral, retroviral, and lentiviral vectors and the effects of enhanced expression of SOX9," Tissue Engineering, vol. 10, no. 3-4, pp. 575-584, 2004.

[60] S. R. Tew, Y. Li, P. Pothancharoen, L. M. Tweats, R. E. Hawkins, and T. E. Hardingham, "Retroviral transduction with SOX9 enhances re-expression of the chondrocyte phenotype in passaged osteoarthritic human articular chondrocytes," Osteoarthritis and Cartilage, vol. 13, no. 1, pp. 80-89, 2005.

[61] H. Enomoto, M. Enomoto-Iwamoto, M. Iwamoto et al., " $\mathrm{Cbfa} 1$ is a positive regulatory factor in chondrocyte maturation," Journal of Biological Chemistry, vol. 275, no. 12, pp. 8695-8702, 2000.

[62] M. Iwamoto, J. Kitagaki, Y. Tamamura et al., "Runx2 expression and action in chondrocytes are regulated by retinoid signaling and parathyroid hormone-related peptide (PTHrP)," Osteoarthritis and Cartilage, vol. 11, no. 1, pp. 6-15, 2003.

[63] P. J. Doherty, H. Zhang, L. Tremblay, V. Manolopoulos, and K. W. Marshall, "Resurfacing of articular cartilage explants with genetically-modified human chondrocytes in vitro," Osteoarthritis and Cartilage, vol. 6, no. 3, pp. 153-160, 1998.

[64] H. Madry, D. Zurakowski, and S. B. Trippel, "Overexpression of human insulin-like growth factor-I promotes new tissue formation in an ex vivo model of articular chondrocyte transplantation," Gene Therapy, vol. 8, no. 19, pp. 1443-1449, 2001.

[65] H. Madry, G. Emkey, D. Zurakowski, and S. B. Trippel, "Overexpression of human fibroblast growth factor 2 stimulates cell proliferation in an ex vivo model of articular chondrocyte transplantation," Journal of Gene Medicine, vol. 6, no. 2, pp. 238-245, 2004.

[66] M. Cucchiarini, T. Thurn, A. Weimer, D. Kohn, E. F. Terwilliger, and H. Madry, "Restoration of the extracellular matrix in human osteoarthritic articular cartilage by overexpression 
of the transcription factor SOX9," Arthritis and Rheumatism, vol. 56, no. 1, pp. 158-167, 2007.

[67] V. M. Baragi, R. R. Renkiewicz, H. Jordan, J. Bonadio, J. W. Hartman, and B. J. Roessler, "Transplantation of transduced chondrocytes protects articular cartilage from interleukin 1induced extracellular matrix degradation," Journal of Clinical Investigation, vol. 96, no. 5, pp. 2454-2460, 1995.

[68] V. M. Baragi, R. R. Renkiewicz, L. Qiu et al., "Transplantation of adenovirally transduced allogeneic chondrocytes into articular cartilage defects in vivo," Osteoarthritis and Cartilage, vol. 5, no. 4, pp. 275-282, 1997.

[69] T. Ikeda, T. Kubo, Y. Arai et al., "Adenovirus mediated gene delivery to the joints of guinea pigs," Journal of Rheumatology, vol. 25, no. 9, pp. 1666-1673, 1998.

[70] R. Kang, T. Marui, S. C. Ghivizzani et al., "Ex vivo gene transfer to chondrocytes in full-thickness articular cartilage defects: a feasibility study," Osteoarthritis and Cartilage, vol. 5, no. 2, pp. 139-143, 1997.

[71] H. Madry, M. Cucchiarini, U. Stein et al., "Sustained transgene expression in cartilage defects in vivo after transplantation of articular chondrocytes modified by lipid-mediated gene transfer in a gel suspension delivery system," Journal of Gene Medicine, vol. 5, no. 6, pp. 502-509, 2003.

[72] S. M. Richardson, J. M. Curran, R. Chen et al., "The differentiation of bone marrow mesenchymal stem cells into chondrocyte-like cells on poly-l-lactic acid (PLLA) scaffolds," Biomaterials, vol. 27, no. 22, pp. 4069-4078, 2006.

[73] S. M. Richardson, R. V. Walker, S. Parker et al., "Intervertebral disc cell-mediated mesenchymal stem cell differentiation," Stem Cells, vol. 24, no. 3, pp. 707-716, 2006.

[74] M. F. Pittenger, A. M. Mackay, S. C. Beck et al., "Multilineage potential of adult human mesenchymal stem cells," Science, vol. 284, no. 5411, pp. 143-147, 1999.

[75] T. L. Arinzeh, "Mesenchymal stem cells for bone repair: preclinical studies and potential orthopedic applications," Foot and Ankle Clinics, vol. 10, no. 4, pp. 651-665, 2005.

[76] L. Hong, A. Colpan, and I. A. Peptan, "Modulations of 17$\beta$ estradiol on osteogenic and adipogenic differentiations of human mesenchymal stem cells," Tissue Engineering, vol. 12, no. 10, pp. 2747-2753, 2006.

[77] D. Noël, F. Djouad, and C. Jorgensen, "Regenerative medicine through mesenchymal stem cells for bone and cartilage repair," Current Opinion in Investigational Drugs, vol. 3, no. 7, pp. 1000-1004, 2002.

[78] F. P. Barry and J. M. Murphy, "Mesenchymal stem cells: clinical applications and biological characterization," International Journal of Biochemistry and Cell Biology, vol. 36, no. 4, pp. 568-584, 2004.

[79] A. I. Caplan, "Adult mesenchymal stem cells for tissue engineering versus regenerative medicine," Journal of Cellular Physiology, vol. 213, no. 2, pp. 341-347, 2007.

[80] W. Sonoyama, Y. Liu, D. Fang et al., "Mesenchymal stem cellmediated functional tooth regeneration in Swine," PLoS One, vol. 1, no. 1, article no. e79, 2006.

[81] O. Trubiani, R. Di Primio, T. Traini et al., "Morphological and cytofluorimetric analysis of adult mesenchymal stem cells expanded ex vivo from periodontal ligament," International Journal of Immunopathology and Pharmacology, vol. 18, no. 2, pp. 213-221, 2005.

[82] O. Trubiani, G. Orsini, S. Caputi, and A. Piattelli, "Adult mesenchymal stem cells in dental research: a new approach for tissue engineering," International Journal of Immunopathology and Pharmacology, vol. 19, no. 3, pp. 451-460, 2006.
[83] M. N. Helder, M. Knippenberg, J. Klein-Nulend, and P. I. J. M. Wuisman, "Stem cells from adipose tissue allow challenging new concepts for regenerative medicine," Tissue Engineering, vol. 13, no. 8, pp. 1799-1808, 2007.

[84] S. M. Richardson, A. Mobasheri, A. J. Freemont, and J. A. Hoyland, "Intervertebral disc biology, degeneration and novel tissue engineering and regenerative medicine therapies," Histology and histopathology, vol. 22, no. 9, pp. 10331041, 2007.

[85] A. E. Grigoriadis, J. N. M. Heersche, and J. E. Aubin, “Differentiation of muscle, fat, cartilage, and bone from progenitor cells present in a bone-derived clonal cell population: effect of dexamethasone," Journal of Cell Biology, vol. 106, no. 6, pp. 2139-2151, 1988.

[86] C. Csaki, N. Keshishzadeh, K. Fischer, and M. Shakibaei, "Regulation of inflammation signalling by resveratrol in human chondrocytes in vitro," Biochemical Pharmacology, vol. 75, no. 3, pp. 677-687, 2008.

[87] C. Csaki, U. Matis, A. Mobasheri, and M. Shakibaei, "Coculture of canine mesenchymal stem cells with primary bonederived osteoblasts promotes osteogenic differentiation," Histochemistry and Cell Biology, vol. 131, no. 2, pp. 251-266, 2009.

[88] A. Mobasheri, C. Csaki, A. L. Clutterbuck, M. Rahmanzadeh, and M. Shakibaei, "Mesenchymal stem cells in connective tissue engineering and regenerative medicine: applications in cartilage repair and osteoarthritis therapy," Histology and Histopathology, vol. 24, no. 3, pp. 347-366, 2009.

[89] T. Fukumoto, J. W. Sperling, A. Sanyal et al., "Combined effects of insulin-like growth factor-1 and transforming growth factor- $\beta 1$ on periosteal mesenchymal cells during chondrogenesis in vitro," Osteoarthritis and Cartilage, vol. 11, no. 1, pp. 55-64, 2003.

[90] H.-L. Ma, S.-C. Hung, S.-Y. Lin, Y.-L. Chen, and W.-H. Lo, "Chondrogenesis of human mesenchymal stem cells encapsulated in alginate beads," Journal of Biomedical Materials Research A, vol. 64, no. 2, pp. 273-281, 2003.

[91] B. Johnstone, T. M. Hering, A. I. Caplan, V. M. Goldberg, and J. U. Yoo, "In vitro chondrogenesis of bone marrow-derived mesenchymal progenitor cells," Experimental Cell Research, vol. 238, no. 1, pp. 265-272, 1998.

[92] H. Jian, X. Shen, I. Liu, M. Semenov, X. He, and X. F. Wang, "Smad3-dependent nuclear translocation of $\beta$-catenin is required for TGF- $\beta 1$ - induced proliferation of bone marrowderived adult human mesenchymal stem cells," Genes and Development, vol. 20, no. 6, pp. 666-674, 2006.

[93] S. Zhou, K. Eid, and J. Glowacki, "Cooperation between TGF- $\beta$ and Wnt pathways during chondrocyte and adipocyte differentiation of human marrow stromal cells," Journal of Bone and Mineral Research, vol. 19, no. 3, pp. 463-470, 2004.

[94] M. Chiou, Y. Xu, and M. T. Longaker, "Mitogenic and chondrogenic effects of fibroblast growth factor-2 in adiposederived mesenchymal cells," Biochemical and Biophysical Research Communications, vol. 343, no. 2, pp. 644-652, 2006.

[95] M. Knippenberg, M. N. Helder, B. Zandieh Doulabi, P. I. J. M. Wuisman, and J. Klein-Nulend, "Osteogenesis versus chondrogenesis by BMP-2 and BMP-7 in adipose stem cells," Biochemical and Biophysical Research Communications, vol. 342, no. 3, pp. 902-908, 2006.

[96] L. Longobardi, L. O’Rear, S. Aakula et al., "Effect of IGF-I in the chondrogenesis of bone marrow mesenchymal stem cells in the presence or absence of TGF- $\beta$ signaling," Journal of Bone and Mineral Research, vol. 21, no. 4, pp. 626-636, 2006. 
[97] L. A. Solchaga, K. Penick, J. D. Porter, V. M. Goldberg, A. I. Caplan, and J. F. Welter, "FGF-2 enhances the mitotic and chondrogenic potentials of human adult bone marrowderived mesenchymal stem cells," Journal of Cellular Physiology, vol. 203, no. 2, pp. 398-409, 2005.

[98] S. Murakami, M. Kan, W. L. McKeehan, and B. De Crombrugghe, "Up-regulation of the chondrogenic Sox9 gene by fibroblast growth factors is mediated by the mitogenactivated protein kinase pathway," Proceedings of the National Academy of Sciences of the United States of America, vol. 97, no. 3, pp. 1113-1118, 2000.

[99] S. R. Tew, P. Pothacharoen, T. Katopodi, and T. E. Hardingham, "SOX9 transduction increases chondroitin sulfate synthesis in cultured human articular chondrocytes without altering glycosyltransferase and sulfotransferase transcription," Biochemical Journal, vol. 414, no. 2, pp. 231-236, 2008.

[100] H. Tsuchiya, H. Kitoh, F. Sugiura, and N. Ishiguro, "Chondrogenesis enhanced by overexpression of sox9 gene in mouse bone marrow-derived mesenchymal stem cells," Biochemical and Biophysical Research Communications, vol. 301, no. 2, pp. 338-343, 2003.

[101] J. I. Sive, P. Baird, M. Jeziorsk, A. Watkins, J. A. Hoyland, and A. J. Freemont, "Expression of chondrocyte markers by cells of normal and degenerate intervertebral discs," Molecular Pathology, vol. 55, no. 2, pp. 91-97, 2002.

[102] J. U. Yoo, T. S. Barthel, K. Nishimura et al., "The chondrogenic potential of human bone-marrow-derived mesenchymal progenitor cells," Journal of Bone and Joint Surgery A, vol. 80, no. 12, pp. 1745-1757, 1998.

[103] N. Boos, A. G. Nerlich, I. Wiest, K. Von Der Mark, and M. Aebi, "Immunolocalization of type X collagen in human lumbar intervertebral discs during ageing and degeneration," Histochemistry and Cell Biology, vol. 108, no. 6, pp. 471-480, 1997.

[104] J. C. Gan, P. Ducheyne, E. J. Vresilovic, W. Swaim, and I. M. Shapiro, "Intervertebral disc tissue engineering I: characterization of the nucleus pulposus," Clinical Orthopaedics and Related Research, no. 411, pp. 305-314, 2003.

[105] K. Pelttari, A. Winter, E. Steck et al., "Premature induction of hypertrophy during in vitro chondrogenesis of human mesenchymal stem cells correlates with calcification and vascular invasion after ectopic transplantation in SCID mice," Arthritis and Rheumatism, vol. 54, no. 10, pp. 32543266, 2006.

[106] Y.-J. Kim, H.-J. Kim, and G.-I. Im, "PTHrP promotes chondrogenesis and suppresses hypertrophy from both bone marrow-derived and adipose tissue-derived MSCs," Biochemical and Biophysical Research Communications, vol. 373, no. 1, pp. 104-108, 2008.

[107] I. Sekiya, B. L. Larson, J. T. Vuoristo, R. L. Reger, and D. J. Prockop, "Comparison of effect of BMP-2, -4 , and -6 on in vitro cartilage formation of human adult stem cells from bone marrow stroma," Cell and Tissue Research, vol. 320, no. 2, pp. 269-276, 2005.

[108] F. Franceschi, U. G. Longo, L. Ruzzini, A. Marinozzi, N. Maffulli, and V. Denaro, "Simultaneous arthroscopic implantation of autologous chondrocytes and high tibial osteotomy for tibial chondral defects in the varus knee," Knee, vol. 15, no. 4, pp. 309-313, 2008.

[109] W. S. Khan and U. G. Longo, "ACI and MACI procedures for cartilage repair utilise mesenchymal stem cells rather than chondrocytes," Medical Hypotheses, vol. 77, no. 2, p. 309, 2011.
[110] U. G. Longo, F. Forriol, N. Maffulli, and V. Denaro, "Evaluation of histological scoring systems for tissue-engineered, repaired and osteoarthritic cartilage," Osteoarthritis and Cartilage, vol. 18, no. 7, p. 1001, 2010.

[111] U. G. Longo, A. Berton, S. Alexander, N. Maffulli, A. L. Wallace, and V. Denaro, "Biological resurfacing for early osteoarthritis of the shoulder," Sports Medicine and Arthroscopy Review, vol. 19, no. 4, pp. 380-394, 2011.

[112] C. Becher, A. Driessen, T. Hess, U. G. Longo, N. Maffulli, and H. Thermann, "Microfracture for chondral defects of the talus: maintenance of early results at midterm follow-up," Knee Surgery, Sports Traumatology, Arthroscopy, vol. 18, no. 5, pp. 656-663, 2010.

[113] F. Forriol, U. G. Longo, E. Alvarez et al., "Scanty integration of osteochondral allografts cryopreserved at low temperatures with dimethyl sulfoxide," Knee Surgery, Sports Traumatology, Arthroscopy, vol. 19, no. 7, pp. 1184-1191, 2011.

[114] U. G. Longo, F. Franceschi, L. Ruzzini, C. Rabitti, M. Nicola, and V. Denaro, "Foreign-body giant-cell reaction at the donor site after autologous osteochondral transplant for cartilaginous lesion. A case report," Journal of Bone and Joint Surgery A, vol. 91, no. 4, pp. 945-949, 2009. 

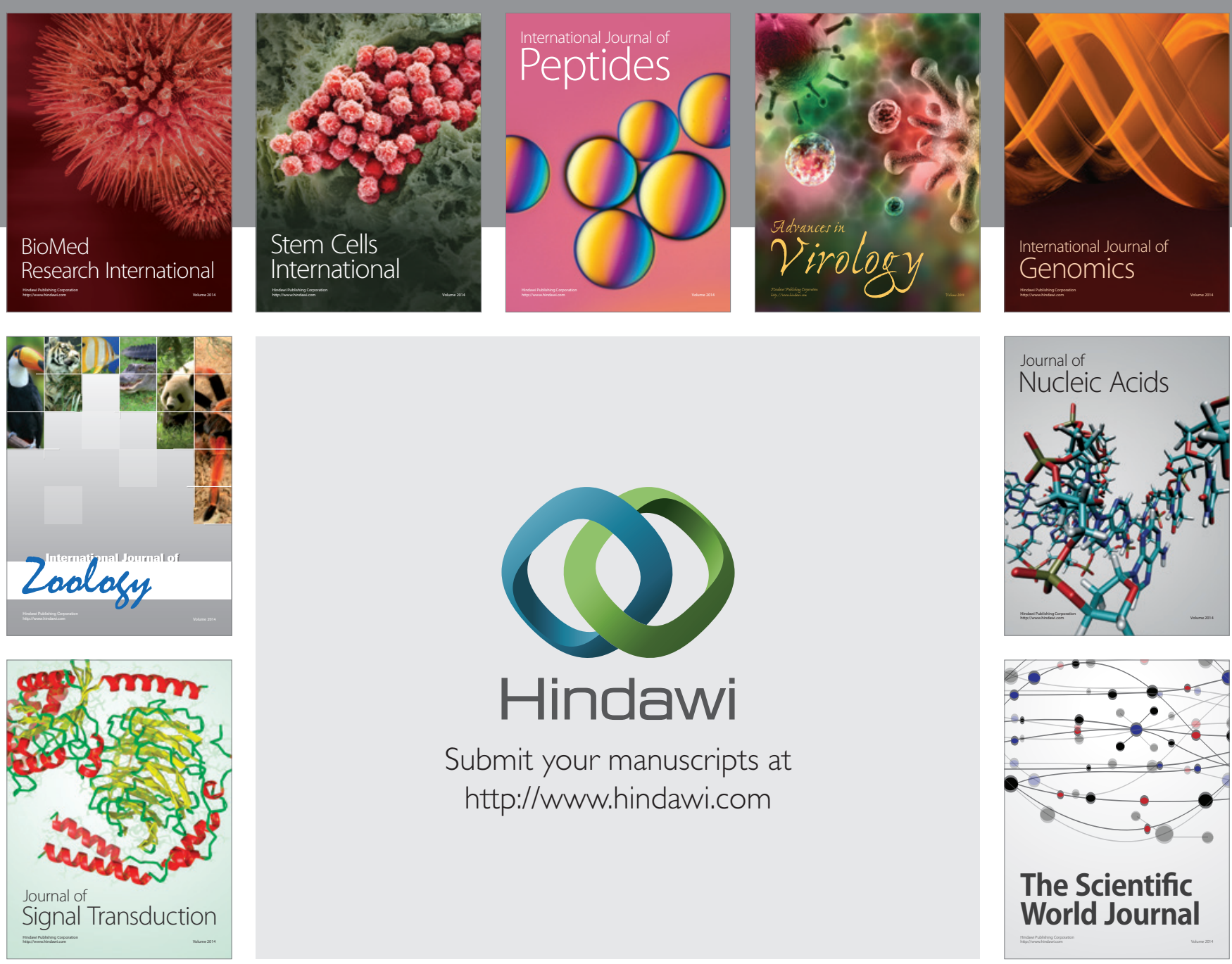

Submit your manuscripts at

http://www.hindawi.com
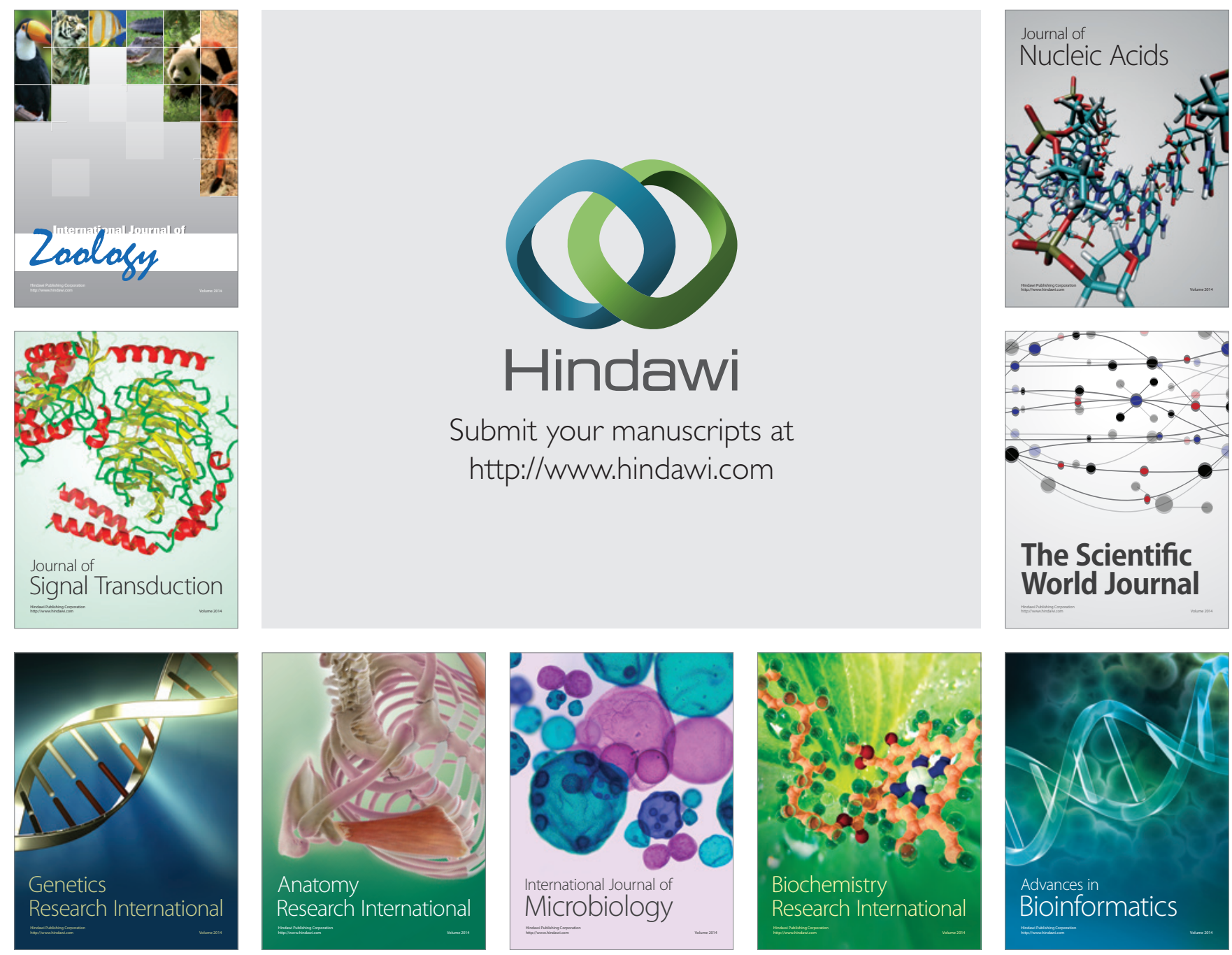

The Scientific World Journal
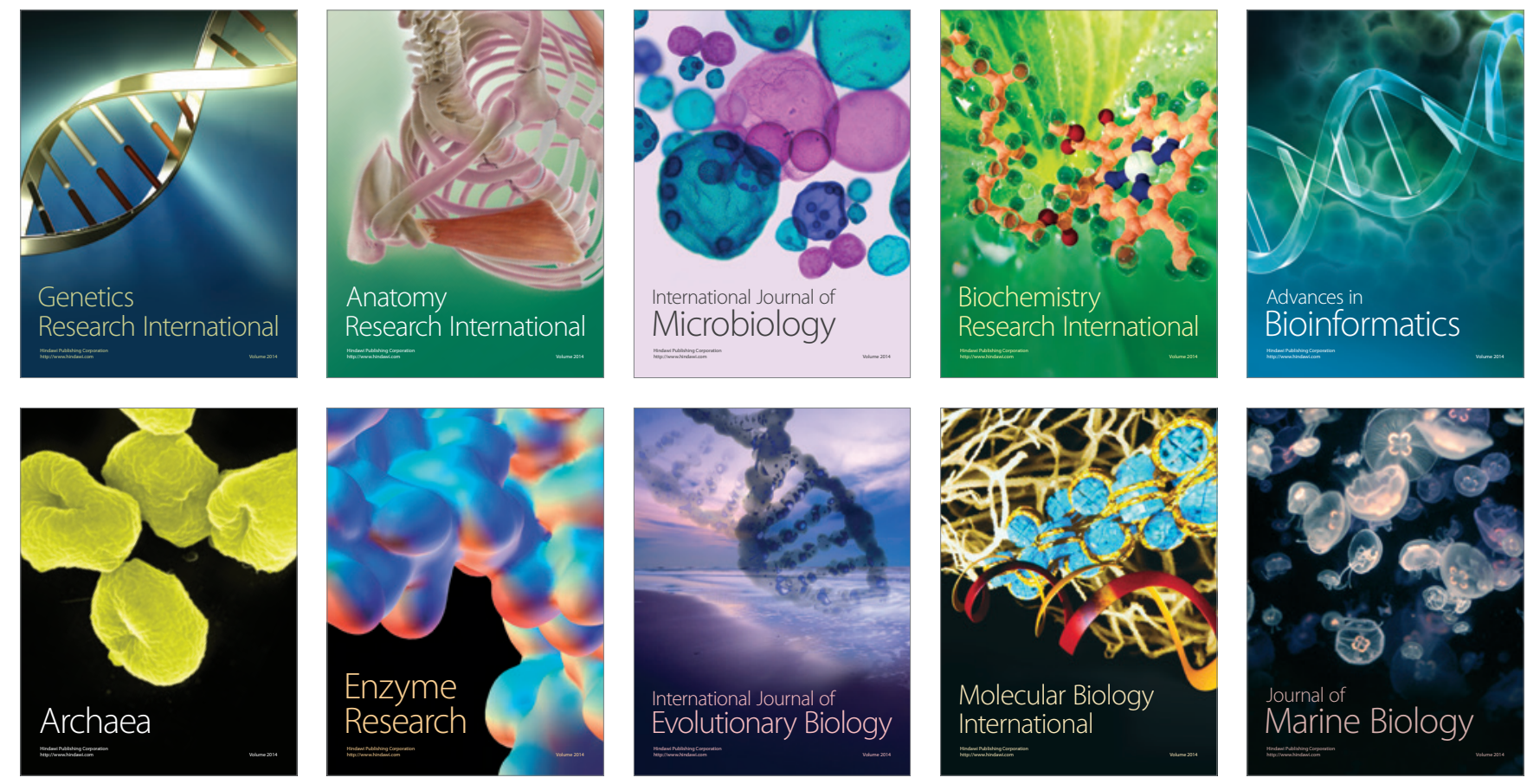